\title{
Identification of G-quadruplex structures that possess transcriptional regulating functions in the Dele and Cdc6 CpG islands
}

\author{
Daniyah H. Bay ${ }^{1,2 \dagger}{ }^{1}$ Annika Busch ${ }^{1,3 \dagger}$, Fred Lisdat ${ }^{3}$, Keisuke lida ${ }^{4}$, Kazunori Ikebukuro ${ }^{5}$, Kazuo Nagasawa ${ }^{5}$, \\ Isao Karube ${ }^{1}$ and Wataru Yoshida ${ }^{1 *}$
}

\begin{abstract}
Background: G-quadruplex is a DNA secondary structure that has been shown to play an important role in biological systems. In a previous study, we identified 1998 G-quadruplex-forming sequences using a mouse CpG islands DNA microarray with a fluorescent-labeled G-quadruplex ligand. Among these putative G-quadruplex-forming sequences, G-quadruplex formation was verified for 10 randomly selected sequences by CD spectroscopy and DMS footprinting analysis. In this study, the biological function of the $10 \mathrm{G}$-quadruplex-forming sequences in the transcriptional regulation has been analyzed using a reporter assay.
\end{abstract}

Results: When G-quadruplex-forming sequences from the Dele and Cdc6 genes have been cloned in reporter vectors carrying a minimal promoter and the luciferase gene, luciferase expression is activated. This has also been detected in experiments applying a promoterless reporter vector. Mutational analysis reveals that guanine bases, which form the G-tetrads, are important in the activation. In addition, the activation has been found to decrease by the telomestatin derivative L1H1-7OTD which can bind to the G-quadruplex DNA. When Dele and Cdc6 CpG islands, containing the G-quadruplex-forming sequence, have been cloned in the promoterless reporter vector, the luciferase expression is activated. Mutational analysis reveals that the expression level is decreased by mutation on Dele G-quadruplex; however, increased by mutation on Cdc6 G-quadruplex.

Conclusion: Dele and Cdc6 G-quadruplex formation is significant in the transcriptional regulation. Dele and Cdc6 $\mathrm{G}$-quadruplex DNA alone possess enhancer and promotor function. When studied in more complex CpG islands Dele G-quadruplex also demonstrates promotor activity, whereas Cdc6 G-quadruplex may possess a dual function of transcriptional regulation.

Keywords: Cdc6, Dele, G-quadruplex, Transcriptional regulation, 7OTD

\section{Background}

Although genomic DNA usually adopts the canonical double helix structure [1-3], formation of non-canonical DNA structures, such as G-quadruplex (G4) DNA and i-motif, have also been found in human genomic DNA [2, $4,5]$. G4 is a DNA secondary structure that consists of two or more planar guanine tetrads and is stabilized by

\footnotetext{
*Correspondence: yoshidawtr@stf.teu.ac.jp

†Daniyah H. Bay and Annika Busch contributed equally to this work

1 School of Bioscience and Biotechnology, Tokyo University of Technology,

1404-1 Katakuramachi, Hachioji, Tokyo 192-0982, Japan

Full list of author information is available at the end of the article
}

Hoogsteen hydrogen bonds along with a monovalent cation $[3,6-10]$. DNA strand orientation and length of the loop sequences connecting the guanine runs provide a structural diversity to G4 forms, such as parallel, antiparallel, or a mixed structure [2, 9-12]. The characteristic topologies and existence of G4 in significant locations, such as in the telomeres and several promoters, suggest potential functions of G4 structures in gene regulation [13].

G4-forming sequences in promoter regions have been found to play a functional role in the suppression of proto-oncogenes [2, 14], such as $c-M Y C$ [15-18], BCL-2 
[19], VEGF [20], and RET [21]. Several studies on the G4-forming sequence within the nuclease hypersensitivity element III $_{1}\left(\mathrm{NHEIII}_{1}\right)$ of the $c-M Y C$ promoter have reported that mutating the G4-forming sequence destabilizes the G4 structure, resulting in a three-fold increase in basal transcriptional activity of the $c-M Y C$ promoter $[15,16]$. Binding of the $c-M Y C \mathrm{G} 4$ to the cationic porphyrin TMPyP4 resulted in repression of the promoter activity [17]. Nucleolin has been identified as the $c-M Y C$ G4 binding protein that represses $c-M Y C$ expression [18]. The $B C L-2$ gene contains a GC-rich region upstream of the P1 promoter that has been shown to be critically involved in the regulation of the $B C L-2$ gene expression. It has been demonstrated that three individual G4 structures can be formed in this GC-rich region [19, 22]. As for $V E G F$, the stabilization of G4 DNA by quindoline derivatives represses gene transcription and consequently causes angiogenesis inhibition [20]. In addition, G4 ligands, such as TMPyP4 and telomestatin, have been shown to stabilize the G4 structure of the RET protooncogene promoter and lead to the repression of gene expression [21].

On the other hand, there are few examples of the transcriptional activation by G4 formation. A recent study of p32 G4 structure that is located in the P1 promoter of the $\mathrm{Bcl}-2$ gene has demonstrated that reduced transcription activity in the mutated vectors compared to the native vectors [23]. This result implicated a transcriptional activation by the G4 structure. Furthermore, in the insulinlinked polymorphic region (ILPR), G4 DNA is formed by a two-repeats of consensus sequence [24, 25], and the G-quartet formation was observed to activate transcription, where single/double mutation in the sequence has reduced promoter activity [26-28]. In addition, the G4-forming $c-m y b$ GGA repeat region has shown to play a contrast role of both a transcriptional repressor and an activator, where one or two deletions of (GGA) ${ }_{4}$ motifs have increased $c-m y b$ promoter activity, while the deletion of all three regions has eliminated the promoter activity [29]. The involvement of G4 structures in regulating the transcription process suggests that they may hold the key to new therapeutic approaches in numerous areas of human disease, including cancer [30].

A genome-wide in silico analysis has demonstrated that sequences with the potential to form G4 motifs are enriched near transcription start sites, in the telomeres, ribosomal DNA, immunoglobulin heavy-chain switch regions, and CpG islands (CGIs) [31-33], suggesting widespread regulatory influence of the G4 motifs [34]. In a previous study, we identified 1998 G4-forming sequences in mouse CGIs using a mouse CGI microarray with a fluorescent-labeled G4 ligand L1Cy5-7OTD [35]. Among the identified G4-forming sequences, CD spectroscopy and DMS footprinting analysis were performed on 10 randomly selected G4-forming sequences and the G4 structure formation was confirmed. In this study, our aim was to analyze the biological function of the $10 \mathrm{G} 4$ DNAs the in transcriptional regulation.

\section{Results \\ Dele and Cdc6 G4-forming sequences activate reporter gene expression}

The 10 G4 DNA sequences from Jard2, Foxa2, Med4, Chd4, Ntpcr, Bmi1, Wt1, Sp130, Cdc6, and Dele genes (Table 1; Additional file 1) have been cloned into the luciferase reporter vector with a minimal promoter containing a TATA-box promoter element. The sequences were 42-50 nucleotides long. The successful plasmid construction has been verified by gel shift experiments and sequencing of the reporter vector.

The Dele G4-forming sequence was found on two divergently overlapping genes, Dele and 1700086O06Rik, located on the mouse genome; therefore, Dele G4 has been cloned into the luciferase vector in the forward and reverse direction (Dele-F G4 and Dele-R G4). The reporter vectors have been transfected into NIH3T3 cells and expressed luciferase activity is measured after $48 \mathrm{~h}$ of cultivation. In order to reduce experimental variability the measured enzyme activity has been normalized with respect to the pGL4.74 vector which is coding for Renilla luciferase. The relative luciferase activity with and without G-quadruplex forming sequences is evaluated for a minimum of three transfections. The results of this set of

\section{Table 1 DNA sequences used in this study}

\begin{tabular}{|c|c|}
\hline Name & Sequences $\left(5^{\prime}-3^{\prime}\right)$ \\
\hline & $\begin{array}{l}\text { GTGAGGCTAGGGGGTGGTGGTGGTGGGGGTGAGGAAGGGAAA } \\
\text { GAT }\end{array}$ \\
\hline Dele & $\begin{array}{l}\text { ATAGCGCCAGTGGGTGGGCTTAGATCTGGGAAGGGCGGGACA } \\
\text { GAG }\end{array}$ \\
\hline & $\begin{array}{l}\text { GTCCAGGAAGGCTAGAGGTGGGGGGGCGGGTACCGGTGAAGG } \\
\text { GAG }\end{array}$ \\
\hline Chd4 & $\begin{array}{l}\text { TAAAGAGGAGGGTGGCGGTAGTGGAGGGGGGGGTTGGAGTTG } \\
\text { GTT }\end{array}$ \\
\hline$N$ & $\begin{array}{l}\text { CTTGTGTGTCGGGAAGGGGGGGGGGGGAGCGTTGGAAACGC } \\
\text { ATGC }\end{array}$ \\
\hline Med4 & $\begin{array}{l}\text { ACTTGGGTAGGCGGGCTTGGGAGGCTCCGTTGGACGTGGGGT } \\
\text { CTA }\end{array}$ \\
\hline Bmil & $\begin{array}{l}\text { CACTCTTTTTGGGGTTGGGACTGAGGTGGCGGTCACGCGAGG } \\
\text { ATC }\end{array}$ \\
\hline Wt1 & $\begin{array}{l}\text { AGTAGGGAGCTTTGGAATGAGGGATTAACACTTTGGGGGACTT } \\
\text { AGTC }\end{array}$ \\
\hline Sp130 & $\begin{array}{l}\text { AGGGGTAGGTTGGGTGGTAAGAGGTGGTAAGCGGAGCGGCTG } \\
\text { CTG }\end{array}$ \\
\hline$c d c 6$ & $\begin{array}{l}\text { TGGGGAGGCTGGGTGGAGGACAAAGTAGAAATAAAAATACGG } \\
\text { AAGTAGAT }\end{array}$ \\
\hline
\end{tabular}

Guanine runs, which form the G-quadruplex structures, are shown in bold and mutation sites are underlined 
experiments are compiled in Fig. 1 and show rather high expression values for $C d c 6$, Dele-F and Dele-R.

Mutant vectors have also been constructed and investigated in order to verify that really the G4-forming sequence affects the transcriptional activity. Mutanttype DNAs have been designed by replacing one of the guanine triplets to thymines (Additional file 1). These guanines were reported to be strongly involved in G4 formation [35], which can be verified by CD measurements in this study (see below).

A comparative analysis of expression levels with the G4-forming sequences and the mutant sequences demonstrates a noticeable differences for Foxa2, Med4, Chd4, Ntpcr, Cdc6, Dele-F and, Dele-R, but no significant difference in Jard2, Bmi1, Wt1, and Sp130 (Fig. 1; Additional file 2). These results indicate that these DNA sequences possess an enhancer activity on the luciferase reporter vector, which is connected to the possibility to form specific G4 secondary structures. We focused on $C d c 6$ and Dele G4 DNAs because the G4 DNAs showed a remarkable high activation in wild-type G4 DNAs. Moreover in regards to the statistical analysis, the t-test between wild-type and mutant-type demonstrated that $C d c 6$ and Dele showed more significant difference $(\mathrm{P}<0.0001)$ compared to Foxa2, Med2 $(\mathrm{P}<0.01)$ and Chd4, Ntpcr $(\mathrm{P}<0.001)$; therefore, we performed detail analysis of the Cdc6 and Dele G4 DNAs.

It has been reported that enhancers frequently do not only interact with promoters but also promotor-promotor interaction is feasible, indicating that promoter can also work as enhancer for other gene promoters [36]. To investigate whether Dele and Cdc6 G4 DNAs also possess a promoter activity, they have been cloned into a promoterless vector and then a reporter assay is performed. It is found that Dele-F, Dele-R and Cdc6 G4 DNAs activate luciferase expression in this system. Furthermore, the activation of protein expression is clearly decreased by thymine mutations in the G4 region (Fig. 2; Additional file 3). These results indicate that Dele and Cdc6 G4 DNAs have a role in transcriptional activation, both as a promoter and enhancer. In order to perform this function, the formation of secondary structures seems to be essential.

In order to evaluate the function of Dele and Cdc6 G4 DNAs in CpG islands (CGIs) that may contain more regulatory elements, the 696-bp DNA fragment containing 475-bp Cdc6 CGI and 555-bp DNA fragment containing 477-bp Dele CGI have been cloned into the promoterless vector to analyze the transcriptional activities. The results demonstrate that the luciferase activities have increased more than one order of magnitude by the cloning of Cdc6, Dele-F and Dele-R CGI DNAs (Fig. 3; Additional file 4). The luciferase activities are higher than that of G4 alone cloning vectors, indicating that the CGIs contain cis-regulatory elements outside of the G4 forming regions.

The transcriptional activity of the mutant-type of $C d c 6$ CGI DNA has been found higher than that of the wildtype. This result suggests that $C d c 6$ G4 may possess a dual function of transcriptional regulation, such as $c-m y c$ G4 [16], swinging in both ways as an activator and as a suppressor under the effect of transcriptional factors.

The transcriptional activity of the mutant-type of DeleF CGI DNA has decreased compared to the wild-type.

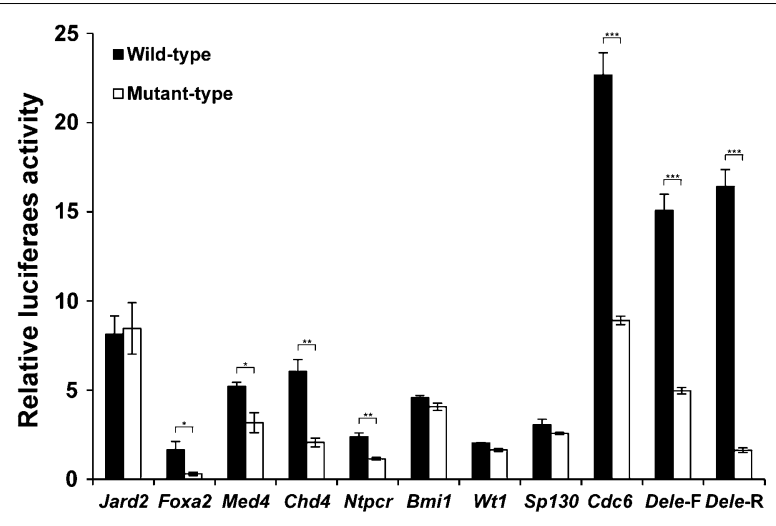

Fig. 1 Luciferase reporter assay for evaluation of the enhancer activities of G4 DNA sequences. The G4-forming sequences were cloned into the $\mathrm{pGL} 4.23$ vector containing minimal promoter. Black bars represent the wild-types and white bars represent the mutanttypes. Luciferase activities relative to the $p G L 4.23$ vector are shown (mean $\pm S D, n=3$ ). Wild- and mutant-types samples t-test differences: ${ }^{*} P<0.01$, ${ }^{* * P}<0.001$, ${ }^{* * *} P<0.0001$

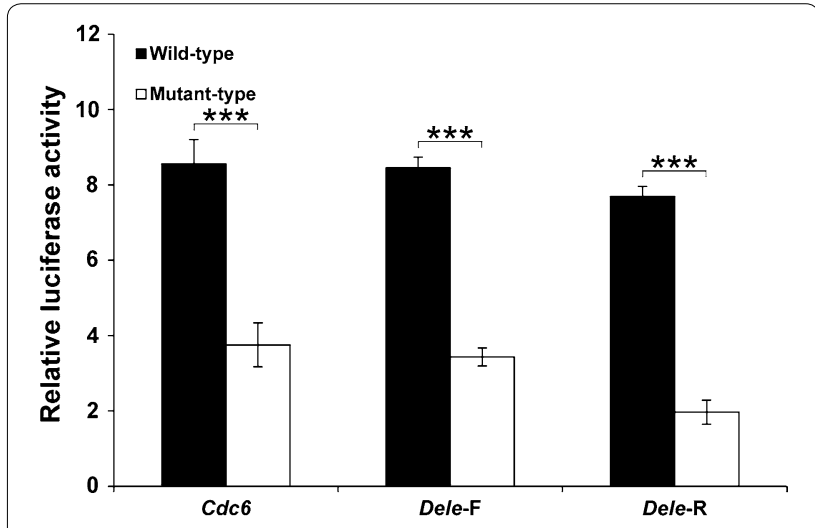

Fig. 2 Reporter assay for evaluation of the promoter activities of $C d c 6$, Dele-F, and Dele-R G4 DNAs. The G4-forming sequences were cloned into the pGL4.10 vector not containing any promoter. Black bars represent the wild-types and white bars represent the mutanttypes. Luciferase activities relative to the $\mathrm{pGL} 4.10$ vector are shown (mean $\pm S D, n=3$ ). Wild- and mutant-types samples t-test differences: ${ }^{* * *} \mathrm{P}<0.0001$ 


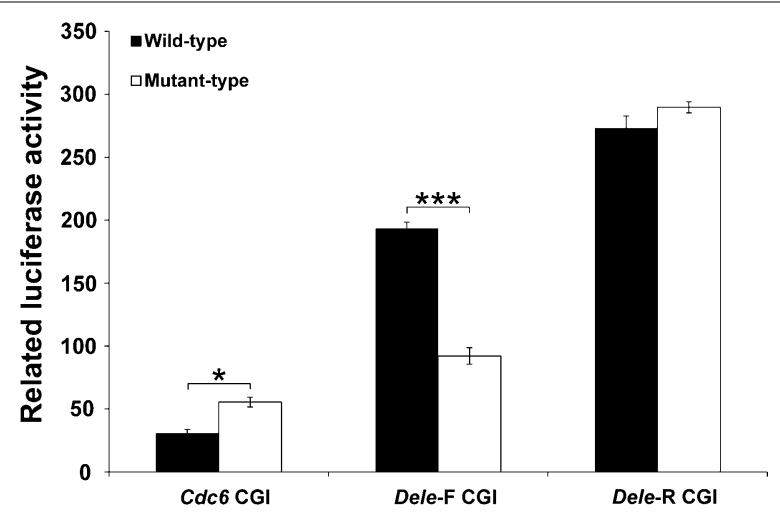

Fig. 3 Reporter assay for evaluation of the transcriptional activity of Cdc6, Dele-F, and Dele-R G4 DNAs in CGI sequences. Black bars represent the wild-types and white bars represent the mutant-types. Luciferase activity relative to the $\mathrm{pGL} 4.10$ is shown (mean $\pm S D$, $n=3$ ). Wild- and mutant-types samples t-test differences: ${ }^{*} P<0.01$, ***P $<0.0001$

In contrast to Dele-F, the transcriptional activity of the Dele-R CGI mutant-type remains similar to that of the wild-type. Two divergently overlapping genes, Dele and 1700086O06Rik, are located on the Dele CGI, suggesting that the Dele CGI may contain at least two regulatory sequences. Our results indicate that the Dele CGI contains a promoter for $1700086006 \mathrm{Rik}$, an insulator, and a promoter for Dele (that also possesses enhancer activity). The insulator sequence may have a blocking activity that prevents promoter-enhancer interaction [37]; therefore, the enhancer activity of the Dele G4 for 1700086006Rik promoter has not been detected.

\section{G4 ligand suppresses the transcriptional activation of Dele and Cdc6 G4 DNAs}

Ligands which can bind to G-quadruplex structures can have different effect on the secondary DNA structure. Distortion or stabilization is often found depending on the binding mode of the ligand. Here the effect of a telomestatin derivative L1H1-7OTD has been investigated with respect to the effect of the G4 ligand on the transcriptional activity of the G4 DNA. This ligand can bind to the top G-tetrad structure through $\pi$-stacking and electrostatic interaction [38, 39].

In a first set of experiments, reporter assays with DeleF, Dele-R and Cdc6 G4 DNA reporter vectors carrying a minimal promoter have been performed in the presence of L1H1-7OTD. The vectors have been transfected into NIH3T3 cells and then the medium has been changed to the medium containing the G4 ligand 1 day after the transfection. After the 1 day cultivation, the luciferase activity has been measured. In this assay, results with L1H1-7OTD-treated and -untreated cells are normalized with L1H1-7OTD-treated and -untreated controls, respectively. As a result, there has been no significant difference of luciferase activity in the presence and the absence of the ligand (Additional file 5). One reason for this could be that the G4 ligand can not easily enter the cells. Therefore in a second set of experiments, the vectors have been mixed with the G4 ligand first and then transfected into NIH3T3 cells in the presence of the G4 ligand in the medium. The results show an inhibition of the luciferase expression with the wild-types of the G4 ligand-treated Dele-F and Cdc6 G4 DNAs, whereas no significant changes have been detected with all the mutant vectors (Fig. 4; Additional file 6). Although CD measurements show a stabilizing effect of the L1H17OTD binding to the G quadruplex (see below), this has no beneficial effect on the activation of protein expression. In this moment one can only hypothesize that the ligand binding to the top of the G4 structure modifies the interaction of the DNA structure with respective transcription factors by influencing the dynamics, the charge and the steric conditions.

\section{CD spectroscopy analyses of Dele and Cdc6 G4 structures}

$\mathrm{CD}$ spectra analysis has been performed to confirm the secondary structure formation of the wild- and mutanttype of Dele and Cdc6 G4 DNA (Fig. 5; Additional file 7). The CD spectra of the wild-types show a positive cotton effect at around $264 \mathrm{~nm}$ for Dele G4 DNA, and at around $262 \mathrm{~nm}$ for $C d c 6$ G4 DNA, with a negative effect at around $242 \mathrm{~nm}$ for Dele G4 DNA, and at around $240 \mathrm{~nm}$ for $C d c 6$ G4 DNA. Thus, the G quadruplex formation can be confirmed under these experimental conditions.

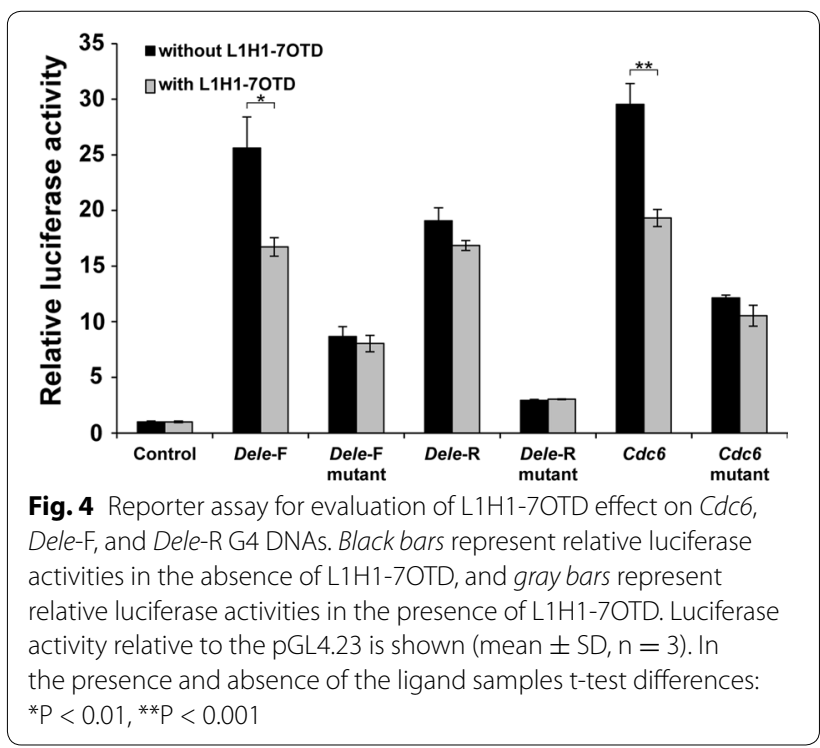



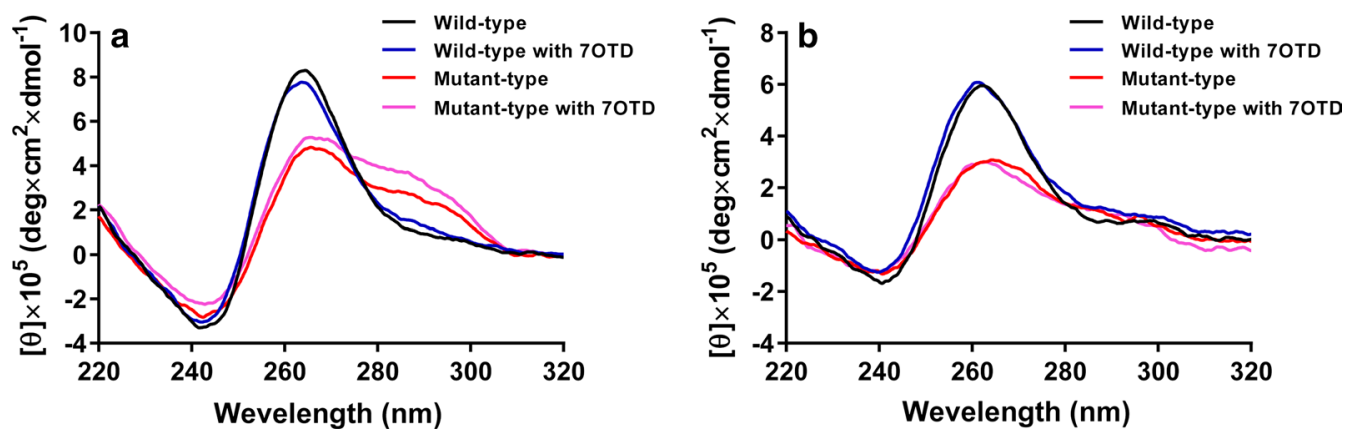

Fig. 5 CD spectra of the Dele G4 (a) and Cdc6 G4 DNAs (b). The wild-type (black), mutant-type (red), wild-type with L1H1-7OTD (blue), and mutanttype with L1H1-7OTD (pink) were analyzed at $25^{\circ} \mathrm{C}$ in TK buffer $(50 \mathrm{mM}$ Tris- $\mathrm{HCl}, 100 \mathrm{mM} \mathrm{KCl}$, pH 7.5)

In the presence of the G4 ligand (L1H1-7OTD), these spectra do not change much, indicating that the formation of parallel-type G4 structures in the wild-types of Dele and Cdc6 G4 DNAs is not disturbed by the presence of the ligand (Additional files 8, 9) [40]. CD melting analysis reveals that the $T_{\mathrm{m}}$ values are $70{ }^{\circ} \mathrm{C}$ for Dele G4 DNA and $77^{\circ} \mathrm{C}$ for $C d c 6$ G4 DNA in the absence of the G4 ligand, while the $T_{\mathrm{m}}$ values increase to $72{ }^{\circ} \mathrm{C}$ for Dele G4 DNA, and to $81{ }^{\circ} \mathrm{C}$ for Cdc6 G4 DNA by addition of the G4 ligand. These are clear arguments that the ligand binding to the G4 structure of the Dele and Cdc6 increases the stability of the G4s at least under the chosen experimental conditions (Fig. 6; Additional file 10). The findings are in agreement with an NMR study on a structurally similar macrocyclic compound L2H2-6M(2) OTD, which has been found to bind to the top G-tetrad structure through $\pi$-stacking and electrostatic interaction. Here the folding topology did not change upon ligand binding [41].

CD spectra of the mutant-type sequences (mutating one G-run to T-run) that may form transient secondary structures, show only low molar ellipticity at around $260 \mathrm{~nm}$ and a shoulder between 280 and $300 \mathrm{~nm}$, which are not related to the characteristic G4 structures (Fig. 5; Additional files 8, 9). Additionally in the presence of the G4 ligand, the CD spectra of the mutant-type sequences are not affected. These results strongly support the G4 formation of the two wild-type sequences of Dele and $C d c 6$ and also verify the disability of the selected mutants to form such defined secondary structures. In consequence, the conclusions, which have been taken from the comparative analysis of mutated and wild type sequences, seem to be valid.

\section{Discussion}

Recently, the death ligand signal enhancer (DELE) has been identified as a binding protein for the death-associated protein 3 (DAP 3), which is induced by various stimuli to regulate cell apoptosis. Stable expression of DELE induces apoptosis, whereas the knockdown of DELE has rescued HeLa cells from apoptosis induction [42]. It has also been reported that the cell-division-cycle 6 (CDC6) protein is essential for DNA replication, and the downregulation of the $C d c 6$ gene causes inhibition in cell growth accompanied by an increase in cell apoptosis [43]. Abnormal apoptosis is related to many diseases involving
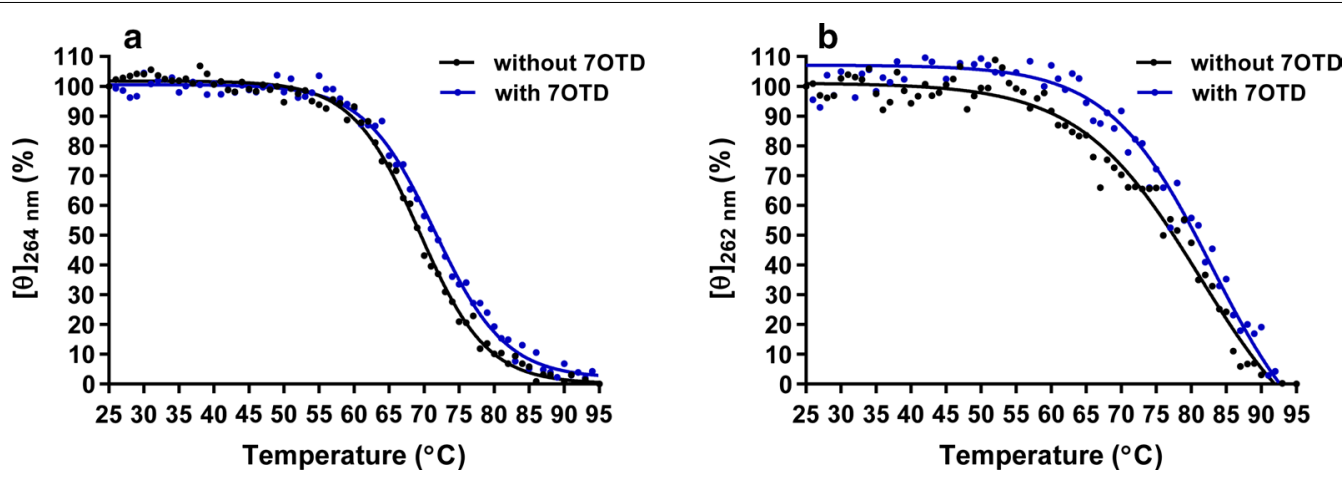

Fig. 6 Circular dichroism melting curves of wild-types of Dele G4 (a) and Cdc6 G4 DNAs (b) at 264 and 262 nm, respectively, with (blue) and without the ligand (black) in TK buffer ( $50 \mathrm{mM}$ Tris- $\mathrm{HCl}, 100 \mathrm{mM} \mathrm{KCl}, \mathrm{pH} 7.5)$ 
atrophy [44], such as Parkinson's disease [45], with excessive cell death leading to tissue and organ damage. In contrast, some oncogenic mutations disrupt apoptosis, leading to tumor progression [46] or metastasis. Therefore, further analysis of Dele and Cdc6 G4 DNAs may contribute to elucidate the apoptosis mechanism.

\section{Conclusions}

The reporter assay for G4-forming DNA sequences has demonstrated that Dele and Cdc6 G4 DNA may have the role of promoter and enhancer i.e., activating the transcription. This can be concluded from comparative experiments with mutant DNA structures. CD spectra verify the G4 formation of the wild type sequences and the disability of the studied mutants to form this secondary structure. The activation of transcription is inhibited by the telomestatin derivative L1H1-7OTD. CD spectra analysis demonstrates that binding of L1H1-7OTD stabilizes the G4 structures, but will also influence interaction with transcription factors. While for Dele-F G4 DNA transcriptional activation has also been verified in experiments with this sequence in CpG islands (CGIs), the $C d c 6$ G4 DNA results here in suppression of protein expression. This indicates that Cdc6 G4 may perform a dual functional role in the transcriptional regulation. In summary the results obtained suggest that Dele and $C d c 6$ G4 structures are formed under physiological conditions in the cell and play a role in regulating transcription. Consequently, the study contributes to the elucidation of mechanisms of Dele and $C d c 6$ gene regulation.

\section{Methods}

\section{Plasmid construction}

The G4 DNAs and mutant-type DNAs (Additional file 1) were cloned in the SfiI site of the pGL4.23 [luc2/ minP] or pGL4.10 [luc2] (Promega Corporation, Madison, WI, USA) and then transformed into E. coli $\mathrm{DH} 5 \alpha$ (TOYOBO, Osaka, Japan). The plasmids were purified by PureYield Plasmid Miniprep System (Promega Corporation, Madison, WI, USA). E. coli HST04 dam-/dcm(Takara, Tokyo, Japan) was transformed by the plasmids to prepare DNA methylation-free plasmids. All plasmids were sequenced using a 3730xl DNA analyzer (Thermo Fisher Scientific, Waltham, MA, USA). The Dele and Cdc6 CGIs were amplified from C57BL/6 mouse genomic DNA by PCR. The PCR primers are shown in Additional file 11. The PCR products were purified by Wizard SV Gel and PCR Clean-Up System (Promega Corporation, Madison, WI, USA) and then digested by Sfi (NEB, Ipswich, MA, USA). The products were cloned in the SfiI site of pGL4.10 [luc2] and the plasmids were prepared as described above. To construct the mutant-types vectors, the site-directed mutagenesis was performed using KOD -plus- mutagenesis kit (TOYOBO, Osaka, Japan) according to manufacturer's protocol (Additional file 11).

\section{Cell culture}

NIH3T3 cells (RCB1862, RIKEN BRC) were cultured in dulbecco modified eagle medium (DMEM) medium (Sigma-Aldrich, St. Louis, Missouri, USA) containing $10 \%$ fetal bovine serum (Sigma-Aldrich, St. Louis, Missouri, USA), $1 \times$ penicillin-streptomycin-L-glutamine solution (Wako, Tokyo, Japan) at $37^{\circ} \mathrm{C}$ in $5 \% \mathrm{CO}_{2}$.

\section{Reporter assay}

The NIH3T3 cells were transfected with $100 \mathrm{ng}$ of the firefly luciferase reporter vector and $100 \mathrm{ng}$ of the Renilla luciferase control vector by Lipofectamine 3000 (Thermo Fisher Scientific, Waltham, MA, USA) according to the manufacturer's protocol. After $48 \mathrm{~h}$, cells were harvested, and luciferase activities were measured using the DualLuciferase Reporter Assay System (Promega Corporation, Madison, WI, USA) and SPARK $10 \mathrm{M}$ microplate reader (TECAN, Männedorf, Switzerland). The ratio of firefly luciferase activity to Renilla luciferase activity was utilized to calculate the firefly luciferase expression level in each cell and then these results were normalized with that of the pGL4.10 or pGL4.23 luciferase reporter vector. All reporter assays were performed in triplicate.

In the experiment to analyze the G4 ligand effect, two methods were used. In the first method, the $100 \mathrm{ng}$ of the firefly luciferase reporter vector, and $100 \mathrm{ng}$ of the Renilla control vector were transfected into NIH3T3 cells by Lipofectamine 3000 . After $24 \mathrm{~h}$, the medium was changed to one with $10 \mu \mathrm{M}$ G4 ligand L1H1-7OTD. After $24 \mathrm{~h}$, the luciferase activity was measured as described above. In the second method, the culture medium was changed to one with $10 \mu \mathrm{M}$ G4 ligand L1H1-7OTD prior to transfection. The NIH3T3 cells were transfected with $100 \mathrm{ng}$ of the firefly luciferase reporter vector, $100 \mathrm{ng}$ of the Renilla control vector, and $10 \mu \mathrm{M}$ of the G4 ligand L1H1-7OTD by Lipofectamine 3000, after which the luciferase activity was measured as described above. The luciferase expression level in the presence or absence of L1H1-7OTD was normalized with that of the pGL4.23 luciferase reporter vector in the presence or absence of L1H1-7OTD, respectively. All reporter assays were performed in triplicate.

\section{CD spectra measurement}

Wild-types and mutant-types of the Dele and Cdc6 G4 oligonucleotides were purchased from Macrogen, South Korea (Additional file 7). The oligonucleotides were dissolved as to create stock solutions $(100 \mu \mathrm{M})$ in distilled water. Prior to use, all oligonucleotides were diluted to $15 \mu \mathrm{M}$ in TK buffer $(50 \mathrm{mM}$ Tris- $\mathrm{HCl}, 100 \mathrm{mM} \mathrm{KCl}$, 
$\mathrm{pH}$ 7.5). The oligonucleotides were denatured at $95{ }^{\circ} \mathrm{C}$ for $3 \mathrm{~min}$ and then allowed to cool to room temperature for $30 \mathrm{~min}$. After heat-treatment, the oligonucleotides were diluted to $10 \mu \mathrm{M}$ in the presence or absence of $10 \mu \mathrm{M} \mathrm{L1H1-7OTD,} \mathrm{and} \mathrm{then} \mathrm{incubated} \mathrm{for} 10 \mathrm{~min}$ before measurement. The $\mathrm{CD}$ spectra were measured with a J-1500 CD Spectrometer (JASCO, Tokyo, Japan) at 220 to $320 \mathrm{~nm}$ using a $1 \mathrm{~mm}$ path-length cuvette at every $5{ }^{\circ} \mathrm{C}$ from 20 to $95{ }^{\circ} \mathrm{C}$. The baseline of each spectrum was corrected for signal contributions by the buffer with and without the G4 ligand. In the CD melting analysis, molar ellipticities were measured concomitantly at $1{ }^{\circ} \mathrm{C}$ intervals for wild-types of Dele and Cdc6 G4 DNAs, at $264 \mathrm{~nm}$ and $262 \mathrm{~nm}$, respectively. To determine $T_{\mathrm{m}}$ values, the molar ellipticity at $25{ }^{\circ} \mathrm{C}$ was set as $100 \%$, and the molar ellipticity at $95{ }^{\circ} \mathrm{C}$ was set as $0 \%$. Using GhraphPad Prism7 software, curve fitting was performed to yield normalized molar ellipticities. $T_{\mathrm{m}}$ values were recorded as temperatures equivalent to $50 \%$ of the normalized molar ellipticity.

\section{Additional files}

Additional file 1. G4 DNA sequences used in the reporter assay.

Additional file 2. Luciferase reporter assay results of G4 DNA sequences cloned in PGL4.23 vector.

Additional file 3. Luciferase reporter assay results of G4 DNA sequences cloned in $\mathrm{PGL} 4.10$ vector.

Additional file 4. Luciferase reporter assay results of CGI DNA sequences cloned in $\mathrm{PGL} 4.10$ vector.

Additional file 5. Luciferase reporter assay results with or without $\mathrm{L} 1 \mathrm{H} 1$ 7OTD for G4 DNA sequences cloned in pGL4.23 vector.

Additional file 6. Luciferase reporter assay results with or without $\mathrm{L} 1 \mathrm{H} 1$ 7OTD for G4 DNA sequences cloned in PGL4.23 vector.

Additional file 7. G4 DNA sequences used in the CD Spectroscopy.

Additional file 8. CD spectra results of Dele G4 DNA wild or mutant-type sequences with or without L1H1-7OTD.

Additional file 9. CD spectra results of Cdc6 G4 DNA wild-type sequence with or without L1H1-7OTD.

Additional file 10. Detailed molar ellipticity of wild-types of Dele and Cdc6 G4 DNAs in the absence and the presence of L1H1-7OTD.

Additional file 11. Primer sequences used for CGI vectors construction and mutagenesis.

\section{Abbreviations}

7OTD: 7 oxazole telomestatin derivative; CD: circular dichroism; Cdc6: celldivision-cycle 6; CpG: cytosine-phosphate-guanine; Dele: death ligand signal enhancer; G4: G-quadruplex.

\section{Authors' contributions}

WY conceived and designed the experiments. $\mathrm{DHB}$ and $\mathrm{AB}$ performed the experiments. DHB, AB, FL, Kli, KIk, KN, IK, and WY analyzed the data. DHB, FL and WY wrote the manuscript. All authors read and approved the final manuscript.

\section{Author details}

${ }^{1}$ School of Bioscience and Biotechnology, Tokyo University of Technology, 1404-1 Katakuramachi, Hachioji, Tokyo 192-0982, Japan. ${ }^{2}$ Biology Department, Umm Al-Qura University, Makkah, Kingdom of Saudi Arabia. ${ }^{3}$ Biosystems Technology, Institute of Applied Life Sciences, Technical University of Applied Sciences Wildau, Wildau, Germany. ${ }^{4}$ Graduate School of Science and Engineering, Saitama University, c/o Saitama Cancer Center, Saitama, Japan.

${ }^{5}$ Department of Biotechnology and Life Science, Tokyo University of Agriculture and Technology, Tokyo, Japan.

\section{Acknowledgements}

We thank Dr. Tomohiko Yamazaki (National Institute for Materials Science, Japan) for the kind gift of $\mathrm{NIH} 3 \mathrm{T3}$ cells.

\section{Competing interests}

The authors declare that they have no competing interests.

\section{Availability of data and materials}

The datasets supporting the conclusions of this article are included within the additional files.

\section{Funding}

This study was supported by Tokyo University of Technology. The funding body had no role in the design of the study, collection, analysis, interpretation of data and in writing the manuscript.

\section{Publisher's Note}

Springer Nature remains neutral with regard to jurisdictional claims in published maps and institutional affiliations.

Received: 19 May 2017 Accepted: 23 June 2017

Published online: 27 June 2017

\section{References}

1. Watson JD, Crick FH. Molecular structure of nucleic acids; a structure for deoxyribose nucleic acid. Nature. 1953;171:737-8.

2. Qin Y, Hurley LH. Structures, folding patterns, and functions of intramolecular DNA G-quadruplexes found in eukaryotic promoter regions. Biochimie. 2008;90:1149-71.

3. Hardin CC, Watson T, Corregan M, Bailey C. Cation-dependent transition between the quadruplex and Watson-Crick hairpin forms of d(CGCG3GCG). Biochemistry. 1992;31:833-41.

4. Phan AT, Mergny JL. Human telomeric DNA: G-quadruplex, i-motif and Watson-Crick double helix. Nucleic Acids Res. 2002;30:4618-25.

5. Simone R, Fratta P, Neidle S, Parkinson GN, Isaacs AM. G-quadruplexes: emerging roles in neurodegenerative diseases and the non-coding transcriptome. FEBS Lett. 2015;589:1653-68.

6. Gellert M, Lipsett MN, Davies DR. Helix formation by guanylic acid. Proc Natl Acad Sci USA. 1962;48:2013-8.

7. Williamson JR, Raghuraman MK, Cech TR. Monovalent cation-induced structure of telomeric DNA: the G-quartet model. Cell. 1989:59:871-80.

8. Parkinson GN, Lee MP, Neidle S. Crystal structure of parallel quadruplexes from human telomeric DNA. Nature. 2002:417:876-80.

9. Duquette ML, Handa P, Vincent JA, Taylor AF, Maizels N. Intracellular transcription of G-rich DNAs induces formation of G-loops, novel structures containing G4 DNA. Genes Dev. 2004;18:1618-29.

10. Schlachter C, Lisdat F, Frohme M, Erdmann VA, Konthur Z, Lehrach $H$, et al. Pushing the detection limits: the evanescent field in surface plasmon resonance and analyte-induced folding observation of long human telomeric repeats. Biosens Bioelectron. 2012;31:571-4.

11. Maizels N, Gray LT. The G4 genome. PLoS Genet. 2013;9:e1003468.

12. Agrawal P, Hatzakis E, Guo K, Carver M, Yang D. Solution structure of the major G-quadruplex formed in the human VEGF promoter in $\mathrm{K}+$ : insights into loop interactions of the parallel G-quadruplexes. Nucleic Acids Res. 2013:41:10584-92.

13. Bochman ML, Paeschke K, Zakian VA. DNA secondary structures: stability and function of G-quadruplex structures. Nat Rev Genet. 2012;13:770-80. 
14. Brooks TA, Kendrick S, Hurley LH. Making sense of G-quadruplex and i-motif functions in oncogene promoters. FEBS J. 2010;277:3459-69.

15. Siddiqui-Jain A, Grand CL, Bearss DJ, Hurley LH. Direct evidence for a G-quadruplex in a promoter region and its targeting with a small molecule to repress c-MYC transcription. Proc Natl Acad Sci USA. 2002;99:11593-8.

16. Borgognone M, Armas P, Calcaterra NB. Cellular nucleic-acid-binding protein, a transcriptional enhancer of c-Myc, promotes the formation of parallel G-quadruplexes. Biochem J. 2010;428:491-8.

17. Seenisamy J, Rezler EM, Powell TJ, Tye D, Gokhale V, Joshi CS, et al. The dynamic character of the G-quadruplex element in the c-MYC promoter and modification by TMPyP4. J Am Chem Soc. 2004;126:8702-9.

18. Gonzalez V, Guo K, Hurley L, Sun D. Identification and characterization of nucleolin as a c-myc G-quadruplex-binding protein. J Biol Chem. 2009;284:23622-35.

19. Wang XD, Ou TM, Lu YJ, Li Z, Xu Z, Xi C, et al. Turning off transcription of the $b c /-2$ gene by stabilizing the $b c l-2$ promoter quadruplex with quindoline derivatives. J Med Chem Soc. 2010;53:4390-8.

20. Wu Y, Zan LP, Wang XD, Lu YJ, Ou TM, Lin J, et al. Stabilization of VEGF G-quadruplex and inhibition of angiogenesis by quindoline derivatives. Biochim Biophys Acta. 2014;1840:2970-7.

21. Guo K, Pourpak A, Beetz-Rogers K, Gokhale V, Sun D, Hurley LH. Formation of pseudosymmetrical G-quadruplex and i-motif structures in the proximal promoter region of the RET oncogene. J Am Chem Soc. 2007;129:10220-8.

22. Dexheimer TS, Sun D, Hurley LH. Deconvoluting the structural and drugrecognition complexity of the $\mathrm{G}$-quadruplex-forming region upstream of the bcl-2 P1 promoter. J Am Chem Soc. 2006;128:5404-15.

23. Sun H, Xiang J, Shi Y, Yang Q, Guan A, Li Q, et al. A newly identified $\mathrm{G}$-quadruplex as a potential target regulating $\mathrm{BCl}-2$ expression. Biochim Biophys Acta. 2014;1840:3052-7.

24. Dhakal S, Yu Z, Konik R, Cui Y, Koirala D, Mao H. G-quadruplex and i-motif are mutually exclusive in ILPR double-stranded DNA. Biophys J. 2012;102:2575-84.

25. Connor AC, Frederick KA, Morgan EJ, McGown LB. Insulin capture by an insulin-linked polymorphic region G-quadruplex DNA oligonucleotide. J Am Chem Soc. 2006;128:4986-91

26. Verma A, Yadav VK, Basundra R, Kumar A, Chowdhury S. Evidence of genome-wide G4 DNA-mediated gene expression in human cancer cells. Nucleic Acids Res. 2009;37:4194-204.

27. Catasti P, Chen X, Moyzis RK, Bradbury EM, Gupta G. Structure-function correlations of the insulin-linked polymorphic region. J Mol Biol. 1996;264:534-45.

28. Timmer CM, Michmerhuizen NL, Witte AB, Van Winkle M, Zhou D, Sinniah K. An isothermal titration and differential scanning calorimetry study of the G-quadruplex DNA-insulin interaction. J Phys Chem B. 2014;118:1784-90.

29. Palumbo SL, Memmott RM, Uribe DJ, Krotova-Khan Y, Hurley LH, Ebbing haus SW. A novel G-quadruplex-forming GGA repeat region in the c-myb promoter is a critical regulator of promoter activity. Nucleic Acids Res. 2008:36:1755-69.

30. Balasubramanian S, Neidle S. G-quadruplex nucleic acids as therapeutic targets. Curr Opin Chem Biol. 2009:13:345-53.
31. Huppert JL, Balasubramanian S. G-quadruplexes in promoters throughout the human genome. Nucleic Acids Res. 2007;35:406-13.

32. Zhao Y, Du Z, Li N. Extensive selection for the enrichment of G4 DNA motifs in transcriptional regulatory regions of warm blooded animals. FEBS Lett. 2007:581:1951-6.

33. Eddy J, Maizels N. Conserved elements with potential to form polymorphic G-quadruplex structures in the first intron of human genes. Nucleic Acids Res. 2008;36:1321-33.

34. Verma A, Halder K, Halder R, Yadav V, Rawal P, Thakur RK, et al. Genomewide computational and expression analyses reveal G-quadruplex DNA motifs as conserved cis-regulatory elements in human and related species. J Med Chem. 2008;51:5641-9.

35. Iida K, Nakamura T, Yoshida W, Tera M, Nakabayashi K, Hata K, et al. Fluorescent-ligand-mediated screening of G-quadruplex structures using a DNA microarray. Angew Chem Int Ed Engl. 2013;52:12052-5.

36. Li G, Ruan X, Auerbach RK, Sandhu KS, Zheng M, Wang P, et al. Extensive promoter-centered chromatin interactions provide a topological basis for transcription regulation. Cell. 2012;148:84-98.

37. Yoshida W, Tomokawa J, Inaki M, Kimura H, Onodera M, Hata K, Nakabayashi K. An insulator element located at the cyclin B1 interacting protein 1 gene locus is highly conserved among mammalian species. PLOS ONE. 2015:10:e0131204.

38. Iida K, Nagasawa K. Macrocyclic polyoxazoles as G-quadruplex ligands. Chem Rec. 2013;13:539-48.

39. Tera M, lida K, Ishizuka H, Takagi M, Suganuma M, Doi T, et al. Synthesis of a potent G-quadruplex-binding macrocyclic heptaoxazole. ChemBioChem. 2009:10:431-5

40. Karsisiotis Al, Hessari NM, Novellino E, Spada GP, Randazzo A, Webba da Silva M. Topological characterization of nucleic acid G-quadruplexes by UV absorption and circular dichroism. Angew Chem Int Ed Engl. 2011:50:10645-8.

41. Chung WJ, Heddi B, Tera M, lida K, Nagasawa K, Phan AT. Solution structure of an intramolecular $(3+1)$ human telomeric G-quadruplex bound to a telomestatin derivative. J Am Chem Soc. 2013;135:13495-501.

42. Harada T, Iwai A, Miyazaki T. Identification of DELE, a novel DAP3-binding protein which is crucial for death receptor-mediated apoptosis induction. Apoptosis. 2010;15:1247-55.

43. Feng CJ, Lu XW, Luo DY, Li HJ, Guo JB. Knockdown of Cdc6 inhibits proliferation of tongue squamous cell carcinoma Tca8113 cells. Technol Cancer Res Treat. 2013;12:173-81.

44. Zhang G, Liu K, Ling X, Wang Z, Zou P, Wang X, et al. DBP-induced endoplasmic reticulum stress in male germ cells causes autophagy, which has a cytoprotective role against apoptosis in vitro and in vivo. Toxicol Lett. 2016:245:86-98.

45. Rasheed MZ, Tabassum H, Parvez S. Mitochondrial permeability transition pore: a promising target for the treatment of Parkinson's disease. Protoplasma. 2017;254:33-42.

46. Zakraoui O, Marcinkiewicz C, Aloui Z, Othman H. Lebein, a snake venom disintegrin, suppresses human colon cancer cells proliferation and tumor-induced angiogenesis through cell cycle arrest, apoptosis induction and inhibition of VEGF expression. Mol Carcinog. 2017:56:18-35.

\section{Submit your next manuscript to BioMed Central and we will help you at every step:}

- We accept pre-submission inquiries

- Our selector tool helps you to find the most relevant journal

- We provide round the clock customer support

- Convenient online submission

- Thorough peer review

- Inclusion in PubMed and all major indexing services

- Maximum visibility for your research

Submit your manuscript at www.biomedcentral.com/submit
C BioMed Central 